\title{
Generation of expressed sequence tags, development of microsatellite and single nucleotide polymorphism markers in Primula sieboldii E. Morren (Primulaceae) for analysis of genetic diversity in natural and horticultural populations
}

\author{
Saneyoshi Ueno*1), Yasuko Yoshida ${ }^{2)}$, Yuriko Taguchi' ${ }^{1)}$, Tokuko Ujino-Ihara1), Naoko Kitamoto ${ }^{3)}$, \\ Masanori Honjo ${ }^{4)}$, Ryo Ohsawa ${ }^{2)}$, Izumi Washitani's) and Yoshihiko Tsumura ${ }^{1)}$ \\ 1) Tree Genetics Laboratory, Department of Forest Genetics, Forestry and Forest Products Research Institute, 1 Matsunosato, Tsukuba, \\ Ibaraki 305-8687, Japan \\ 2) Graduate School of Life and Environmental Sciences, University of Tsukuba, 1-1-1 Tennoudai, Tsukuba, Ibaraki 305-8572, Japan \\ 3) Faculty of Agriculture, Iwate University, 3-18-8 Ueda, Morioka, Iwate 020-8550, Japan \\ 4) National Agricultural Research Center for Tohoku Region, 4 Akahira, Shimo-kuriyagawa, Morioka, Iwate 020-0198, Japan \\ 5) Graduate School of Agricultural and Life Science, The University of Tokyo, 1-1-1 Yayoi, Bunkyo, Tokyo 113-8657, Japan
}

\begin{abstract}
Primula sieboldii is a self-incompatible ornamental plant that has been cultivated for more than 300 years in Japan. In order to increase the available genomic resources for this species, 5651 expressed sequence tags (ESTs) were generated from seedling and winter bud cDNA libraries. After clustering and assembling ESTs, 2960 unigene elements that contain an homologous sequence to an $S$ locus-linked gene of $P$. vulgaris were identified. In total, 127 simple sequence repeats (SSRs) were found. The most frequent di- and tri-SSR motifs were GA (78.6\%) and ATT (12.9\%), respectively. Twenty SSR and 40 single nucleotide polymorphism (SNP) markers were developed. These markers were evaluated for polymorphisms using 24 individuals (Y) from a population in Yatsugatake and 14 individuals (PS) from across the distributional range of $P$. sieboldii in Japan. The average level of expected heterozygosity within Y and PS was 0.39 and 0.48 , respectively for EST-SSR markers and 0.26 and 0.29 , respectively for SNP markers. The level of polymorphism for ESTSSR markers was lower than that for genomic SSR markers developed in a previous study. We also surveyed the genetic diversity of 56 cultivars, which had lower allelic richness than the Y and PS populations.
\end{abstract}

Key Words: genetic resource, horticulture, heterostyly, gene ontology, SNP, EST-SSR, SNaPshot.

\section{Introduction}

Primula sieboldii E. Morren belongs to the genus Primula that consists of about 500 species worldwide, 14 of which are wildly distributed in Japan (Washitani 1998). The chromosome base numbers of $12,11,10,9$ and 8 are known for the genus (Richards 2003). P. sieboldii has 12 chromosomes in diploid genome $(2 n=24)$, although triploid and tetraploid cultivars are found (Yamaguchi 1973). The species is a selfincompatible, perennial, clonal herb that grows in moist habitats in diverse places ranging from the understory of deciduous forests to well-managed grasslands in Japan (southern Hokkaido; northern, central and western Honshu and central Kyushu (Honjo et al. 2004)), Korea and Siberia (Yamazaki 1993). It was once listed as 'vulnerable' in the Japanese Plant Red List (Environment Agency of Japan 2000), but has recently been re-classified as 'near-threatened' (Iwatsuki

Communicated by T. Yamamoto

Received November 18, 2010. Accepted May 16, 2011.

*Corresponding author (e-mail: saueno@ffpri.affrc.go.jp)
2008) due to conservation efforts in recent years. Changes in the land use and management and overexploitation dating back to 300 years from Edo era (Torii 1985) have caused the decline of this species.

To assist in the development of effective management plans for the species, ecological, genetic and horticultural researches have been conducted. One hundred and forty-six genomic microsatellite markers have been developed for this species (Isagi et al. 2001, Kitamoto et al. 2005, Ueno et al. $2003,2005,2009 \mathrm{~b}$ ) and used to infer patterns of gene flow (Ishihama et al. 2006, Kitamoto et al. 2006) and to define appropriate conservation units (Honjo et al. 2009, Yoshida et al. 2009) of the species. Because effective conservation plans are important not only for natural populations but also for breeding materials, estimation of the origin of cultivars (Honjo et al. 2008) and genetic analysis of petal traits (Yoshida et al. 2008, Yoshioka et al. 2005) of this species has been conducted. These studies showed the importance of cultivars as a reservoir of genetic diversity and the phenotypic variance under genetic control for some trait.

Research in terms of ecology, genetics, conservation and 
horticulture conducted in recent years provides $P$. sieboldii with a unique opportunity to integrate these research areas to build "Primula study", where genomic approaches will play a key role to elucidate adaptive phenotypic variations under genetic control that dictate the way of species interaction, adaptation to abiotic environments and horticultural cultivation by Japanese (Washitani 1998). In order to understand how genetic variation underlies such phenotypic variation, genetic analyses using functional genes are preferred, because of the possibility of linking gene functions and phenotypes through QTL mapping and association studies where information from functional genes are more fruitful than that from anonymous genomic regions.

Expressed sequence tags (ESTs) are one-pass reads from cDNA libraries that are easily acquired by high throughput sequencing. ESTs often contain coding sequence and their functions can be determined by similarity searches. For organisms with poor genomic resources, like primulas, EST sequencing is an efficient way to access functional genomic sequences. The genus Primula has received special interest in the past because of its heterostyly and self-incompatibility (Darwin 1880). A homology search of ESTs within this genus may identify transcripts that constitute a homologue of the self-incompatibility $(S)$ locus-linked (SLL) genes that have been identified from $P$. vulgaris Hudson (Li et al. 2007).

In the present study we generated cDNA libraries from seedlings and winter buds of $P$. sieboldii. We then collected ESTs and developed simple sequence repeat (SSR) and single nucleotide polymorphism (SNP) markers in order to increase the genomic resources for this species. We then analyzed the genetic variation in natural populations and horticultural collections to evaluate the levels of polymorphism of these markers. We used two sets of individuals from natural populations. One is from a single population that are located in Yatsugatake, Nagano prefecture, where a large number of genets (assemblage of clonally propagated individuals (ramets)) constitute a single conservation unit (Honjo et al. 2009) within which gene flow occurs among subpopulations. The population is well characterized and retains reference population traits in terms of conservation (Kitamoto et al. 2005). Because almost no genetic structure within Yatsugatake population has been confirmed, this population is suited to evaluate the existence of null alleles for neutral genetic markers. Markers with null alleles should be avoided in analysis of genetic structure and parentage. Fourteen individuals in the other set were selected from 14 populations from all over the distributional range of the species in Japan. Levels of polymorphism at the species level can be evaluated by this set of individuals. We also used 56 cultivars to evaluate genetic diversity and to demonstrate the utility of markers developed here. Although the evaluation of genetic diversity for cultivars is not comprehensive because of more than 300 cultivars (Torii 1985) known today, it will give us guidelines for future research plans. The ESTs and makers that we described here will be valuable resources for the analysis of genetic variation of functional genes and may provide insights into the genes relating to phenotypic traits and drive future Primula researches in Japan as well as in other countries.

\section{Materials and Methods}

\section{Source of $m R N A$ and $c D N A$ sequencing}

Two kinds of cDNA library (SL and WB) were constructed for P. sieboldii: the SL library from seedlings, and the WB library from winter buds. For the SL library construction, RNA was extracted from germinated seedlings in October 2003. Seeds were briefly sterilized in a solution containing $0.04 \%$ TritonX and hypochlorous acid (the effective chlorine concentration was more than $0.25 \%$ ), then immersed overnight in $1 \mathrm{mM}$ of gibberellin (KYOWA HAKKO BIO CO., LTD.) and kept in a refrigerator to break dormancy. Seeds were harvested in the summer 2002 from a natural population at Yatsugatake Forest (Nobeyama, Minamimaki-mura, Minamisaku-gun, Nagano Prefecture, Japan). These seeds were sown on MS media and grown in a temperature-controlled incubator with a 12-h photoperiod and a day/night temperature of $12 / 24^{\circ} \mathrm{C}$ to the cotyledon stage just before the leaves turned green. Approximately $0.5 \mathrm{~g}$ of whole seedlings (including roots, shoots and leaves) was harvested during daylight, and immediately frozen in liquid nitrogen and ground to a fine powder using a mortar and pestle. The Aurum Total RNA Mini Kit (Bio-Rad) was used to extract total RNA. The mRNA was recovered using an Oligotex-dT30 Super mRNA purification kit (TAKARA). The ZAP-cDNA Synthesis Kit (Stratagene) was used to construct a cDNA library according to the manufacturer's instructions. We randomly-selected 96 clones that were subjected to rolling circle amplification (RCA) using the TempliPhi Kit (GE Healthcare Bio-Science) and test-sequenced from the $5^{\prime}$ end with dye terminator chemistry using T3 primers and an ABI 3100 Genetic Analyzer (Applied Biosystems). After the redundancy of the library was estimated from the test sequences by conducting an own-blastn search, the rest of the cDNA sequencing was carried out using RCA, sequenced from the $5^{\prime}$ end with dye terminator chemistry using T3 primers and a MegaBACE4000 sequencer (Amersham Bioscience).

For WB library construction, RNA was extracted from winter buds grown in pots filled with vermiculite. The plants originated from a natural population in Hidaka, Hokkaido and were kept in a nursery at the Forestry and Forest Products Research Institute, Tsukuba, Japan, where no air conditioners but automatic water irrigation systems worked. We harvested winter buds in December 2003. Whole plants were washed using tap water to remove the vermiculite. After any excess moisture had been removed from the surface of the plants, roots were cut from the winter buds and the buds were then frozen with liquid nitrogen and ground to a fine powder using a mortar and pestle. The total RNA was extracted using the CTAB method (Chang et al. 1993) and 
purified with an SV Total RNA Isolation System (Promega). The mRNA was recovered using an Oligotex-dT30 Super mRNA purification kit (TAKARA). A cDNA library was constructed using a SMART cDNA Library Construction Kit (Clontech) according to the manufacturer's instructions. After the quality of the library had been checked by sequencing 96 random clones as for the SL library, the rest of the cDNA was sequenced from the $3^{\prime}$ end with dye terminator chemistry using $\mathrm{T} 7$ primers and templates prepared by RCA using a MegaBACE4000 sequencer (Amersham Bioscience).

After sequence chromatograms were delivered, clones with low quality short sequences were re-sequenced from the reverse direction using the same methods described above for the test-sequencing.

\section{Analysis of EST sequences}

Raw chromatograms were subjected to the EST analysis pipelines of trace2dbEST and PartiGene (Parkinson et al. 2004). For the first step of the trace $2 \mathrm{dbEST}$ process, base calling was carried out by Phred (Ewing and Green 1998, Ewing et al. 1998) with an error probability cutoff of 0.05 ; cross_match was used to mask vector, adaptor and Escherichia coli sequences. Poly A/T sequences with more than 12 repeats were also masked. Sequences less than $150 \mathrm{bp}$ long were discarded, while the remaining sequences were tagged as 'high quality' and further cleaned up by the Lucy2 program ( $\mathrm{Li}$ and Chou 2004). The sequences were then clustered and assembled in the PartiGene pipeline by CLOBB (Parkinson et al. 2002) and Phrap (Green 1999), respectively using the default parameters. All singletons (sequences that were not clustered with other sequences by CLOBB) and contigs (sequences produced by PartiGene) were assumed to be unigene elements; these sequences were annotated by Blast2GO ver. 2.3.6 using the default parameters (Conesa et al. 2005, Conesa and Gotz 2008). Homology search was further conducted using TAIR10 peptide databases (available from ftp://ftp.arabidopsis.org/home/tair/ Sequences/blast_datasets/TAIR10_blastsets/TAIR10_pep_ 20101214) with e-value cutoff of 1e-3. Results from an InterProScan (Quevillon et al. 2005) search and an ANNEX (Conesa et al. 2008) analysis were conducted to augment the Gene Ontology (Harris et al. 2004) annotations. Enrichment analysis to identify GO slim terms over-represented in the SL or WB libraries was performed with Fisher's exact tests with the FatiGO tool (Al-Shahrour et al. 2004). The false discovery rate (FDR) cutoff was set at 0.05 with one-tail. Enrichment analysis for each unigene element was also performed using the method described by Audic and Claverie (1997) with an FDR cutoff of 0.05.

In order to identify unigene elements relating to SLL alleles and identify any genes that showed differential expression between pin and thrum flowers, seven sequences (accession numbers: DQ381433-DQ381438 and DQ873304) in P. vulgaris (Li et al. 2007) were downloaded and blasted against the $P$. sieblodii unigene elements by Blastn (Altschul et al. 1990) using e-value cutoff of 1e-10.
Microsatellites or SSRs were mined by the SSRIT program (Temnykh et al. 2001) for those with at least nine, six and five repeat units for di-, tri- and tetra-SSRs, respectively. The locations of the coding regions on each unigene element were estimated from the corresponding peptide translation by ESTScan ver. 2.1 (Iseli et al. 1999).

\section{Development of EST-SSR and SNP markers}

PCR primers for EST-SSRs were designed by Primer3 (Rozen and Skaletsky 2000) with the aid of the read2Marker script (Fukuoka et al. 2005). PCR products were tested using a post-PCR fluorescence-labeling technique (Kondo et al. 2000). For successful primer pairs, polymorphisms were screened for two panels. One panel (Y) consisted of 24 individuals from a single population in Yatsugatake Forest (Nobeyama, Minamimaki-mura, Minamisaku-gun, Nagano prefecture, Japan), while the other panel (PS) consisted of 14 individuals from across the distributional range of $P$. sieboldii in Japan (Supplemental Table 1 and Supplemental Fig. 1). Because the Y panel originated from a single population, we assumed it was in Hardy-Weinberg equilibrium, which provided a rough indication of whether or not null alleles existed. In contrast, the PS population was expected to exhibit polymorphisms at the species level. PCR was carried out in $5 \mu \mathrm{L}$ reaction mixtures containing $10 \mathrm{ng}$ of genomic DNA, $2.5 \mu \mathrm{L}$ of $2 \times$ Multiplex PCR Master Mix (QIAGEN) and $0.2 \mu \mathrm{M}$ of each primer. We used the following PCR conditions: $95^{\circ} \mathrm{C}$ for $15 \mathrm{~min}$, then 40 cycles of $94^{\circ} \mathrm{C}$ for $30 \mathrm{sec}$, $60^{\circ} \mathrm{C}$ for $90 \mathrm{sec}$ and $72^{\circ} \mathrm{C}$ for $60 \mathrm{sec}$, followed by a final extension at $60^{\circ} \mathrm{C}$ for $30 \mathrm{~min}$. PCR products were subjected to electrophoresis on an ABI 3100 Genetic Analyzer and sized by the GeneMapper software ver. 3.7 (Applied Biosystems). The number of alleles $(\mathrm{Na})$, observed heterozygosity $\left(\mathrm{H}_{\mathrm{O}}\right)$, expected heterozygosity $\left(H_{E}\right)$ (Goudet 1995) and fixation in$\operatorname{dex}\left(F_{I S}=1-H_{O} / H_{E}\right)$ (Goudet 1995) were determined for each locus. For the Y population, which is considered to be a random mating population, heterozygote excess and deficiency was tested using Genepop ver. 4 (Rousset 2008) at an FDR level of 0.05 .

SNP markers were developed for ESTs with own-blastn score $<200$. PCR primers were designed by Primer3 (Rozen and Skaletsky 2000). PCR amplification was checked by using a Multiplex Kit (QIAGEN) according to the manufacturer's instructions. PCR products were subjected to electrophoresis on $2 \%$ agarose gels. For primers with a single locus amplification pattern on the agarose gels, PCR was carried out for two individuals in $15 \mu \mathrm{L}$ reaction mixtures containing $1 \times$ buffer, $1.5 \mathrm{mM} \mathrm{MgCl}_{2}, 0.2 \mathrm{mM}$ of each dNTP, $0.2 \mu \mathrm{M}$ primers, 0.5 units of Ex Taq polymerase (TAKARA) and $2-10 \mathrm{ng}$ of template DNA. We used the following PCR program for the amplification: $94^{\circ} \mathrm{C}$ for $3 \mathrm{~min}$; then $40 \mathrm{cy}$ cles of $94^{\circ} \mathrm{C}$ for $45 \mathrm{sec}, 60$ or $65^{\circ} \mathrm{C}$ for $45 \mathrm{sec}$ and $72^{\circ} \mathrm{C}$ for $45 \mathrm{sec}$, followed by a final extension at $72^{\circ} \mathrm{C}$ for $7 \mathrm{~min}$. PCR products were purified with a QIAQuick purification kit (QIAGEN), cycle-sequenced from both directions by BigDye ver. 3.1 and run on an ABI 3100 Genetic Analyzer 
(Applied Biosystems). Sequences were assembled by the Sequencher software (Gene Codes) and primers for the SNaPshot reaction (Applied Biosystems) were designed by visual inspection of polymorphic sites. The location of each SNaPshot site (coding region or intron) was also analyzed by alignment with the corresponding EST and/or unigene element sequence. Open reading frames were identified by referencing the peptide translation with ESTScan ver. 2.1 (Iseli et al. 1999). PolyT sequences were added to the 5' ends of some of the SNaPshot primers for multiplex electrophoresis. SNPs were genotyped for the Y and PS panels using a SNaPshot kit (Applied Biosystems). The templates for SNaPshot reactions were prepared by conducting PCR in $5 \mu \mathrm{L}$ reaction mixtures containing $10 \mathrm{ng}$ of template DNA, $2.5 \mu \mathrm{L}$ of $2 \times$ Multiplex PCR Master Mix (QIAGEN) and $0.2 \mu \mathrm{M}$ of each primer. We used the following PCR program: $95^{\circ} \mathrm{C}$ for $15 \mathrm{~min}$; then 40 cycles of $94^{\circ} \mathrm{C}$ for $30 \mathrm{sec}$, $60^{\circ} \mathrm{C}$ for $90 \mathrm{sec}$ and $72^{\circ} \mathrm{C}$ for $60 \mathrm{sec}$, followed by a final extension at $60^{\circ} \mathrm{C}$ for $30 \mathrm{~min}$. PCR products were again purified by ExoSAP-IT (GE Healthcare Bio-Science) and used for SNaPshot (Applied Biosystems) reactions in $5 \mu \mathrm{L}$ mixtures containing $1.5 \mu \mathrm{L}$ of the purified PCR product, $2.5 \mu \mathrm{L}$ of SNaPshot Multiplex Ready Reaction Mix (Applied Biosystems) and $0.2 \mu \mathrm{M}$ of each primer using the following PCR program: $96^{\circ} \mathrm{C}$ for $2 \mathrm{~min}$; then 25 cycles of $96^{\circ} \mathrm{C}$ for $10 \mathrm{sec}, 50^{\circ} \mathrm{C}$ for $5 \mathrm{sec}$ and $60^{\circ} \mathrm{C}$ for $30 \mathrm{sec}$, followed by a final extension at $60^{\circ} \mathrm{C}$ for $1 \mathrm{~min}$. The products were again purified by ExoSAP-IT (GE Healthcare Bio-Science) and subjected to electrophoresis on an ABI 3100 Genetic Analyzer (Applied Biosystems). SNPs were genotyped using GeneMapper software ver. 3.7 (Applied Biosystems). Statistics such as $\mathrm{Na}, H_{O}$ and $H_{E}$ and $F_{I S}$ were calculated and any heterozygote excess or deficiency was tested in the same way as for the EST-SSR markers.

Genetic diversity of cultivars by EST-SSR and SNP markers

Genetic diversity was assessed in fifty-six $P$. sieboldii cultivars using the markers that we had developed. The horticultural population that we used was composed of 56 cultivars (Supplemental Table 2), which were kept in the Agricultural and Forestry Research Center, University of Tsukuba and constitutes a part of horticultural collection. The selected 56 cultivars showed a different phenotypes
(Supplemental Table 2) and were not intended to include specific phenotypes. We extracted DNA from the leaves of individual cultivars grown at the Agricultural and Forestry Research Center, University of Tsukuba. PCR and electrophoresis were carried out as described above for both ESTSSR and SNP markers. Genetic diversity was summarized by calculating $\mathrm{Na}, H_{O}$ and $H_{E}$. We also calculated the allelic richness (Ar) (El Mousadik and Petit 1996) because allelic diversity is dependent on the number of samples. These statistics were analyzed for both the Y and PS populations using Friedman tests (Friedman 1937).

\section{Results}

\section{EST sequencing and construction of unigene elements}

In total, 7552 reads were collected from the two libraries: 3630 and 3922 from the seedling (SL) and winter bud (WB) libraries, respectively (Table 1 ). After cleaning with the trace2dbEST and Lucy2 programs, 5651 sequences were used for assembly by the PartiGene program and deposited in the DNA Data Bank of Japan (DDBJ). The number of independent clones included in the assembly was 3259 and 1948 from the SL and WB libraries, respectively. The CLOBB program in the PartiGene package produced 2948 clusters, including 1182 clusters with one EST sequence. After assembling the clusters, 2960 unigene elements were identified. The average and maximum lengths of the unigene elements were $503 \mathrm{bp}$ and $1737 \mathrm{bp}$, respectively. The total length of the unigene elements was approximately $1.48 \mathrm{Mb}$.

Homology searches with the Blastx algorithm against the NCBI nr database by the Blast2GO software found 2106 unigene elements with significant hits at an e-value cutoff level of 1e-3. Functional annotation by Blast2GO resulted in $94 \mathrm{GO}$ slim terms for 1660 (56\%) unigene elements. The most common GO slim terms with respect to Biological process, Cellular component and Molecular function were those involved in cellular process (GO:0009987) and plastid (GO:0009536) and binding (GO:0005488), respectively (Supplemental Table 3). When Blastn searches of $P$. sieblodii unigene elements were carried out for genes relating to SLL (self-incompatibility $(S)$ locus-linked) alleles and a gene showing differential expression between pin and thrum flowers (PF1, as described by Li et al. 2007), we

Table 1. EST sequencing statistics

\begin{tabular}{|c|c|c|c|c|c|c|}
\hline Library & & & No. reads & $\begin{array}{l}\text { No. } \mathrm{HQ}^{a} \\
\text { sequence }\end{array}$ & $\begin{array}{l}\text { Average length } \\
\text { (bp) of HQ }\end{array}$ & Accession No. for HQ \\
\hline \multirow[t]{3}{*}{ Seedling (SL) } & $5^{\prime}$ reads & & 3534 & 3258 & 475 & FS231279-FS228022 \\
\hline & $3^{\prime}$ reads & & 96 & 93 & 630 & FS231280-FS231372 \\
\hline & & Total & 3630 & 3351 & & \\
\hline \multirow[t]{3}{*}{ Winter buds (WB) } & $5^{\prime}$ reads & & 476 & 456 & 475 & FS231373-FS231828 \\
\hline & $3^{\prime}$ reads & & 3446 & 1846 & 376 & FS231829-FS233674 \\
\hline & & Total & 3922 & 2302 & & \\
\hline Total & & & 7552 & 5653 & & \\
\hline
\end{tabular}

${ }^{a}$ High quality sequence were defined by the trace $2 \mathrm{dbEST}$ pipeline. See text for details. 
Table 2. Characteristics of the differentially expressed unigene elements between seedling (SL) and winter bud (WB) cDNA libraries

\begin{tabular}{|c|c|c|c|c|c|c|}
\hline \multirow{2}{*}{$\begin{array}{l}\text { Unigene } \\
\text { element ID }\end{array}$} & \multicolumn{2}{|c|}{ No. of EST clones } & \multicolumn{3}{|c|}{ NR blastx top hit } & \multirow{2}{*}{ GO slim annotation } \\
\hline & SL & WB & Accession & E-value & Description [species] & \\
\hline PsC00075_1 & 22 & 0 & XP_002533768 & $2.56 \mathrm{E}-27$ & $\begin{array}{l}\text { Nonspecific lipid-transfer protein } \\
\mathrm{D} \text {, cotyledon-specific isoform } \\
\text { precursor [Ricinus communis] }\end{array}$ & GO:0006810 \\
\hline PsC00275_1 & 22 & 0 & AAF79822 & 0 & $\begin{array}{l}\text { AC026875_2T6D22.2 } \\
{[\text { Arabidopsis thaliana }]}\end{array}$ & $\begin{array}{l}\text { GO:0003746, GO:0005525, GO:0005634, } \\
\text { GO:0005739, GO:0005516, GO:0006414, } \\
\text { GO:0003924, GO:0005840, GO:0006448 }\end{array}$ \\
\hline PsC00007_1 & 16 & 332 & - & - & - & - \\
\hline PsC00051_1 & 5 & 157 & ACU16378 & $2.84 \mathrm{E}-16$ & Unknown [Glycine max] & - \\
\hline PsC00852_1 & 1 & 116 & XP_002305123 & 4.88E-06 & $\begin{array}{l}\text { Predicted protein [Populus } \\
\text { trichocarpa }]\end{array}$ & - \\
\hline PsC00668_1 & 4 & 45 & ABO36635 & $9.31 \mathrm{E}-19$ & $\begin{array}{l}\text { Defensin protein }[\text { Solanum } \\
\text { lycopersicum }]\end{array}$ & GO:0006952, GO:0008233 \\
\hline PsC00035_1 & 3 & 40 & - & - & - & - \\
\hline PsC02332_1 & 0 & 29 & XP_002314695 & 3.34E-21 & $\begin{array}{l}\text { Predicted protein }[\text { Populus } \\
\text { trichocarpa }]\end{array}$ & GO:0005975, GO:0004462, GO:0006090, \\
\hline PsC02265_1 & 1 & 23 & ABK59915 & $1.35 \mathrm{E}-21$ & $\begin{array}{l}\text { Type- } 2 \text { metallothionein [Aegiceras } \\
\text { corniculatum] }\end{array}$ & GO:0046872 \\
\hline PsC02489_1 & 0 & 14 & XP_002510159 & 0.000731 & $\begin{array}{l}\text { Conserved hypothetical protein } \\
\text { [Ricinus communis }]\end{array}$ & - \\
\hline PsC02393_1 & 0 & 10 & - & - & - & - \\
\hline
\end{tabular}

$a_{-}$: Not available

found one unigene element (PsC02126_1) that showed significant similarity against all three SLL1 1 alleles. There were, however, no $P$. sieboldii unigene elements that showed homology with SLL2 alleles and PF1.

We found 11 unigene elements (Table 2) that showed differential expression between the SL and WB libraries at an FDR of 0.05 according to the method of Audic and Claverie (1997). These unigene elements were similar to: lipid transfer (PsC00075_1); elongation factor (PsC00275_1) proteins in the SL library; allergen (PsC00051 1, although no annotation was found by Blast2GO because of the low annotation score (AS)); defensin (PsC00668_1); auxinrepressed protein (PsC00852 1, with no annotation because of a low AS); lactoylglutathione lyase (PsC02332_1); and methallothionein (PsC0265_1) in the WB library. There was no functional information for any of the other unigene elements. These unigene elements were the second and ninth most expressed representatives in the SL and WB libraries, respectively. There were $178(6.0 \%)$ unigene elements in common between the SL and WB libraries. The SL and WB libraries covered $2220(75.0 \%)$ and $918(31.0 \%)$ of the total unigene elements, respectively. In the enrichment analysis of the GO slim terms by FatiGO, no differences were found between the two libraries. ESTScan translated 2647 $(89 \%)$ unigene elements into peptide sequences, which were assumed to be putative coding regions and were then used for estimating the location of the SSRs and SNPs.

Microsatellite mining and development of EST-SSR markers In total, 127 SSRs were identified in $112(3.8 \%)$ of the P. sieboldii unigene elements (Table 3). Among these, AG
Table 3. Abundance of microsatellites within the 2960 P. sieboldii unigene elements

\begin{tabular}{|c|c|c|c|c|}
\hline \multirow{2}{*}{ SSR } & \multirow{2}{*}{ Motif } & & \multicolumn{2}{|c|}{ Occurrence } \\
\hline & & & Total & Coding \\
\hline & $\mathrm{AC}$ & & 1 & 0 \\
\hline & $\mathrm{AG}$ & & 78 & 0 \\
\hline & $\mathrm{AT}$ & & 16 & 0 \\
\hline & CG & & 0 & 0 \\
\hline \multirow[t]{11}{*}{ di-SSR } & & total & 95 & 0 \\
\hline & AAC & & 6 & 3 \\
\hline & AAG & & 7 & 4 \\
\hline & AAT & & 12 & 3 \\
\hline & $\mathrm{ACC}$ & & 0 & 0 \\
\hline & ACG & & 0 & 0 \\
\hline & ACT & & 0 & 0 \\
\hline & AGC & & 2 & 2 \\
\hline & AGG & & 2 & 2 \\
\hline & ATC & & 0 & 0 \\
\hline & $\mathrm{CCG}$ & & 0 & 0 \\
\hline \multirow[t]{4}{*}{ tri-SSR } & & total & 29 & 14 \\
\hline & AACA & & 1 & 0 \\
\hline & ATTG & & 1 & 0 \\
\hline & ATGT & & 1 & 0 \\
\hline tetra-SSR & & total & 3 & 0 \\
\hline Total & & & 127 & 14 \\
\hline
\end{tabular}

repeats $(61 \%)$ were the most frequent, followed by AT repeats $(13 \%)$. There were no CG repeats in the unigene elements. For tri-SSR motifs, the abundance was much lower, compared to di-SSRs. The maximum number of repeats was 
17 for di-SSRs, 12 for tri-SSRs and seven for tetra-SSRs. The most frequent tri-SSR motif was AAT (9\%) followed by AAG (6\%) and AAC (5\%) motifs. When the location of each SSR was estimated, no di-SSRs were found in coding regions, while $14(48 \%)$ of the tri-SSRs were located in coding regions. Three tetra SSRs (AACA, ATTG and ATGT) were identified, the location of which were identified as being located in non-coding regions.

For EST-SSR marker development, we designed 94 primer pairs based on EST sequences using the read2Marker script, which were expected to amplify SSRs with at least four repeat units. After PCR amplification and preliminary analysis of the resulting electropherograms, 20 primer pairs were selected for population genetic analysis. Putative functions for each SSR were estimated from the Blastx results of the unigene element to which it belonged. Approximately half of the EST-SSR markers had Blast hits (Supplemental Table 4a). There were two EST-SSR markers with locations estimated to be in coding regions.

Polymorphism analysis of the Yatsugatake (Y) and natural (PS) populations revealed that the average numbers of alleles per locus $(\mathrm{Na})$, observed $\left(H_{O}\right)$ and expected $\left(H_{E}\right)$ heterozygosities, and fixation index $\left(F_{I S}\right)$ were $2.75,0.38$, 0.39 and 0.04 , respectively for the Y population, and 3.55, $0.36,0.48$ and 0.20 , respectively for the PS population (Supplemental Table 5a). A significant heterozygote excess was detected for a locus $103 \mathrm{B02}$. One locus $\left(206 C 07^{m}\right)$ was monomorphic in both the $\mathrm{Y}$ and PS populations, while a locus 201 N16 was monomorphic in only the Y population. All of the markers produced products in the expected PCR product size range calculated from the EST sequences (data not shown).

\section{Development of SNP markers}

We designed 192 primer pairs, 102 of which produced stable PCR products when sequenced from both directions. Preliminary polymorphism screening using two individuals identified 40 primer pairs that amplified suitable polymorphic sites for SNaPshot primer design (Supplemental Table 4b). When the location of each SNP was analyzed, nine and 29 SNPs were found to reside within intronic and exonic regions, respectively, while for the remaining two SNPs, the locations could not be determined. These sequences could not be aligned with their corresponding EST and unigene element sequences. Eighteen (45\%) of the exonic SNPs were coding SNPs, five of which were thought to cause amino acid substitution (non-synonymous SNPs). When polymorphisms were screened for the Yatsugatake (Y) and natural (PS) P. sieboldii populations, no loci had more than two alleles. The average values of $\mathrm{Na}, \mathrm{H}_{O}, \mathrm{H}_{E}$ and $F_{I S}$ were $1.83,0.28,0.26$ and 0.01 , respectively for the $\mathrm{Y}$ population and $1.88,0.25,0.29$ and 0.15 , respectively for the PS population. Although SNPs were initially screened for two individuals, three loci $(105 C 15,203 K 07$ and 204B19) were monomorphic in both the $\mathrm{Y}$ and PS populations. One locus (106B11) showed significant heterozygote excess.
Table 4. Mean genetic diversity (number of alleles per locus $(\mathrm{Na})$, observed heterozygosity $\left(H_{O}\right)$ and expected heterozygosity $\left(H_{E}\right)$ ) within horticultural $(\mathrm{H})$, Yatsugatake $(\mathrm{Y})$ and natural (PS) populations using 20 EST-SSR and 40 SNP markers. $A r$ was calculated using 24 and 20 gene copies for EST-SSR and SNP markers, respectively. The $P$ values are based on Friedman tests to compare the mean values among populations

\begin{tabular}{|c|c|c|c|c|c|}
\hline & \multirow{2}{*}{$\begin{array}{c}\text { Marker } \\
\text { type }\end{array}$} & \multicolumn{3}{|c|}{ Population } & \multirow{2}{*}{$P$ value } \\
\hline & & $\mathrm{H}(N=56)$ & $\mathrm{Y}(N=24)$ & PS $(N=14)$ & \\
\hline \multirow[t]{2}{*}{$\mathrm{Na}$} & EST-SSR & 2.95 & 2.75 & 3.55 & 0.015 \\
\hline & SNP & 1.75 & 1.83 & 1.88 & 0.178 \\
\hline \multirow[t]{2}{*}{$A r$} & EST-SSR & 2.64 & 2.54 & 3.43 & $8.45 \mathrm{E}-04$ \\
\hline & SNP & 1.67 & 1.72 & 1.85 & $2.76 \mathrm{E}-05$ \\
\hline \multirow[t]{2}{*}{$\overline{H_{O}}$} & EST-SSR & 0.46 & 0.38 & 0.36 & 0.087 \\
\hline & SNP & 0.25 & 0.28 & 0.25 & 0.864 \\
\hline \multirow[t]{2}{*}{$\overline{H_{E}}$} & EST-SSR & 0.46 & 0.39 & 0.48 & 0.081 \\
\hline & SNP & 0.24 & 0.26 & 0.29 & 0.308 \\
\hline
\end{tabular}

$N$ : number of individuals

When genetic diversities were compared among the SNP sites (exon vs. intron, coding vs. non-coding and synonymous $v s$. non-synonymous), we found no differences in the levels of genetic diversity in both the Y and PS populations (data not shown).

\section{Comparison of genetic diversity among horticultural, Yatsugatake and natural population}

We used the EST-SSR and SNP markers that we had developed to survey the genetic diversity of a horticultural $(\mathrm{H})$ population containing 56 cultivars. Although we had 112 missing genotypes, the average call rate for each marker was $98.3 \%$. Two pairs of cultivars were identical based on the multilocus genotypes of 20 EST-SSR and 40 SNP loci. The mean number of alleles per locus $(\mathrm{Na})$, allelic richness $(\mathrm{Ar})$, observed heterozygosity $\left(H_{O}\right)$ and expected heterozygosity $\left(H_{E}\right)$ were calculated (Table 4$)$. The PS population had the highest values of $\mathrm{Na}$ and $\mathrm{Ar}$ for both marker types. A significant difference (Freidman test, $P=0.015$ ) was found in the mean values of $\mathrm{Na}$ for EST-SSR markers among the H, Y and PS populations. Significant differences in the mean values of $A r$ were detected for both marker types, while the mean values of $H_{O}$ and $H_{E}$ were similar among the three populations for both marker types and the differences were not statistically significant. When the levels of significance were adjusted for multiple tests, $A r$ for both EST-SSR and SNP markers showed significant differences among populations. The value of $A r$ was the highest for the PS population and lowest for the H population. The difference in $A r$ values between the PS and H populations was significant $(P=0.0056$; Wilcoxon test), while that between the $\mathrm{H}$ and $\mathrm{Y}$ populations was not significant. 


\section{Discussion}

cDNA libraries as genome resource for P. sieboldii

We identified 5651 ESTs from the two cDNA libraries and constructed 2960 unigene elements. Before our study, only 19 public ESTs were available for the genus Primula (accessed 14 November, 2010) in the NCBI Genbank database. Our study has greatly increased the EST resources for the Primula genus and has provided sequence information for candidate genes of adaptive importance (Alonso-Blanco et al. 2009) for P. sieboldii. Among such candidates, SLL genes are without doubt one of the most important loci for Primula, not only in terms of breeding, but also for the conservation of natural populations. We identified a homologous sequence of PvSLL1. Because of the differences in the levels of self-incompatibility between the pin and thrum morphs of $P$. sieboldii, Washitani (1996) suggested, following results from her simulation study, that self-pollination due to pollinator losses can cause the depletion of the thrum morphs within a population. Monitoring the morph frequency is therefore important for assessing the conservation status of populations. Molecular marker-based methods better facilitate assessments because the morph type can then be determined irrespective of its life stage. The development of molecular markers for SLL1 will be a focus of future research.

We constructed two cDNA libraries and found genes expressed differentially between the two libraries (Table 2), although the library construction and sequencing statistics (Table 1) were different for the two libraries, with the SL library containing more unique transcripts than the WB library. The highly represented unigene elements in the SL library may reflect the active development of seedlings, while those in the WB library may represent genes that are important during dormancy. Unigene elements that were highly expressed in the WB library may have direct and/or indirect relevance to phenotypic differences in bud initiation for $P$. sieboldii. Because bud initiation has been reported as an adaptive character for $P$. sieboldii (Yoshida et al. 2009), candidate genes for future research should include those relating to bud dormancy and/or initiation, the control of which is important for plant survival (Horvath et al. 2003). The cDNA libraries developed in our study will provide an important resource for future genetic research in $P$. sieboldii.

We developed 20 EST-SSR markers and 40 SNP markers (Supplemental Tables 4, 5). Because these markers are codominant, they have a number of advantages over dominant markers, such as RAPDs and AFLPs, for genetic analysis (Khlestkina and Salina 2006). Since SNPs allow the identification of the most common sources of variation (Chakravarti 2001), they should be used to increase the number of molecular markers for a particular species. There are various kinds of SNP genotyping technologies: Gupta et al. (2008) described 30 types, some of which are suitable for high throughput genotyping where thousands of markers can be examined in parallel. Although the SNaPshot method is only a modest throughput genotyping method (Pati et al. 2004), the application of high throughput genotyping methods is impossible for non-model organisms that lack a complete genome sequence. The construction of other cDNA libraries could be used for more efficient SNP discovery and genotyping, and will allow more ESTs to be identified, which may be needed in the future for $P$. sieboldii.

\section{Mining EST-SSRS}

A total of 127 SSRs were found in 112 unigene elements (Table 3). Because the total number and length of the unigene elements was 2960 and $1.48 \mathrm{Mb}$, respectively, the discovery rate of SSRs was $3.8 \%(=112 / 2960)$, or one SSR every $11.7 \mathrm{~kb}$. The discovery rates of EST-SSRs varies substantially between species, and among dicotyledonous species it ranges from $2.65 \%$ for Solanum tuberosum L. to $16.82 \%$ for Juglans regia L. (Kumpatla and Mukhopadhyay 2005). The occurrence of SSRs in P. sieblodii was relatively low, though thresholds to detect SSRs significantly affect the discovery rate. Even though we compared the SSR discovery rate of $P$. sieboldii with other studies that used the same threshold, the discovery rate is still low. Using the same threshold, the discovery rate for Quercus mongolica var. crispula (Blume) H. Ohashi and Castanopsis sieboldii (Makino) Hatus. ex T. Yamaz. \& Mashiba var. sieboldii was $11.6 \%(=248 / 2140)$ and $11.8 \%(=286 / 2417)$, respectively (Ueno et al. 2008, 2009a). The occurrence of EST-SSRs in $P$. sieboldii was lower and the number of repeats was shorter compared to other species.

In terms of the SSR motifs, AG and AAT were the most abundant for di- and tri-SSRs, respectively (Table 3 ). Among dicotyledonous species, the AG and AAG motifs are the most common di- and tri-SSRs, respectively (Kumpatla and Mukhopadhyay 2005). Even though the threshold for the minimum number of tri-SSRs was set at the same level as described by Kumpatla and Mukhopadhyay (2005) (five for tri-SSRs), the most frequent tri-SSR motif in $P$. sieboldii was still AAT. When the threshold was further lowered to four for tri-SSRs, we found 33 AAG and 32 AAT motif triSSRs in P. sieboldii unigene elements.

\section{Comparison of EST-SSR with genomic SSR markers}

We developed 20 EST-SSR markers for P. sieboldii, 14 of which had at least one di-SSR motif (Supplemental Table 4a). Genomic di-SSR microsatellite markers for this species have already been reported by Ueno et al. (2009b), where 119 di-SSRs were analyzed for polymorphisms in the Yatsugatake and natural populations. The natural population used by Ueno et al. (2009b) was the same as that used in the present study. Moreover, the Yatsugateke population (Ueno et al. 2009b) contained the same 11 individuals used here. Comparison of the genetic diversity between the two studies only reflects the differences in the characteristics of markers without the effects of population structure. Here, we only considered di-SSR markers. When we consider the maximum number of di-SSR repeats for each locus (Supplemental Table $4 \mathrm{a}$ ), the average and maximum repeat numbers of 
Table 5. Comparison of the summary statistics for di-SSR motifs between EST-SSR in the present study and genomic SSR markers from Ueno et al. (2009b). The same 24 individuals from the Yatsugatake (Y) population and 14 individuals from the natural (PS) population were genotyped for both EST-SSR and genomic SSR markers

\begin{tabular}{cccc}
\hline \hline & $\begin{array}{c}\text { EST-SSR } \\
(N=14)\end{array}$ & $\begin{array}{c}\text { Genomic SSR } \\
(N=119)\end{array}$ & Significance $^{a}$ \\
\hline Average no. repeats $^{b}$ & 5.6 & 13.8 & $* * *$ \\
Yatsugatake population(Y) & & & \\
$N a$ & 2.71 & 5.54 & $* * *$ \\
$H_{O}$ & 0.38 & 0.52 & $\mathrm{NS}$ \\
$H_{E}$ & 0.38 & 0.65 & $* *$ \\
Natural population (PS) & & & $* * *$ \\
$N a$ & 3.50 & 7.06 & NS \\
$H_{O}$ & 0.38 & 0.48 & $* *$ \\
$H_{E}$ & 0.47 & 0.74 & \\
\hline
\end{tabular}

${ }^{a}$ Adjusted for multiple comparisons (Holm 1979); NS: non-significant $* *: P<0.01, * * *: P<0.001$

${ }^{b}$ Average no. repeats are based on sequenced alleles.

${ }^{c} N$ : number of loci, $N a$ : number of alleles per locus, $H_{O}$ : observed heterozygosity, $H_{E}$ : expected heterozygosity

sequenced alleles were 5.6 and nine, respectively, and 13.8 and 38 for genomic SSRs (Ueno et al. 2009b). The repeat length was significantly longer for genomic di-SSRs (Table 5). A comparison of the genetic diversities $\left(\mathrm{Na}, \mathrm{H}_{O}\right.$ and $H_{E}$ ) between EST-SSR and genomic SSRs showed significantly higher diversity in $\mathrm{Na}$ and $H_{E}$ for genomic SSRs (Welch's t-test). Similar trends have also been observed for Helianthus annuus L. (Pashley et al. 2006), Oryza sativa L. (Cho et al. 2000), Q. mongolica (Ueno et al. 2008) and C. sieboldii (Ueno et al. 2009a). Because of the functional constraints of ESTs, lower levels of EST-SSR polymorphisms are expected compared to genomic SSRs.

\section{Genetic diversity of cultivars}

We genotyped 56 cultivars and compared the mean values of the four diversity statistics (number of alleles per locus, allelic richness, observed and expected heterozygosity) with those of the Yatsugatake (Y) and natural (PS) populations (Table 4) to test the application of the markers that we developed (Supplemental Table 4). There were no significant differences among populations except for allelic richness. Allelic richness was highest in the PS population and the smallest in the horticultural population. This suggests that horticultural collections do not represent the entire genetic diversity of $P$. sieboldii. Honjo et al. (2008) investigated the origin of 120 horticultural cultivars using assignment tests against natural populations and found that most of the cultivars originated from a single metapopulation, called Asama-Arakawa. These authors also found that $P$. sieboldii cultivars are the result of intraspecific variation without any interspecific crosses. Although not all of the cultivars used in the present study were the same as those used by Honjo et al. (2008), their findings support our results and explain why allelic diversity in the horticultural population is low com- pared to the PS population. Because bottlenecks lead to lower levels of allelic diversity (Leberg 2002), the lower level of allelic richness in the horticultural population that we observed is likely to be the result of selection of $P$. sieboldii cultivars from the Asama-Arakawa metapopulation.

\section{Future perspectives}

This study presented the first EST resource for $P$. sieboldii as well as for the genus Primula. As the sequencing technology is advancing rapidly, the EST sequences will be collected more easily. The second and/or third generation sequencing data will be combined with the sequences collected by the traditional Sanger sequencing method presented here. Combined assembly of sequences collected by different sequencing platforms will improve sequence accuracy as well as transcriptome coverage. Reference sequences, thus constructed, will serve as templates for downstream analysis of, for example, digital gene expression, alternative splice variant and SSR and SNP detections. These genomic resources combined with high throughput genotyping technologies and analysis methods, will further accelerate the breeding, management and conservation of the species. Linkage map construction that permits QTL analysis is under progress (Yoshida et al. 2011), using markers described here. Enrichment of genomic resources will also enable association studies for adaptive characters. Future Primula studies based on adaptive genetic variation, thus identified, may identify key processes for ecology, evolution and horticultural cultivation of this species.

\section{Acknowledgements}

We would like to thank Mihoko Nagai for providing $P$. sieboldii samples, Mai Koyano for laboratory and PC assistance, Kensuke Yoshimura for management of our Linux server, Tomohiro Igasaki for his advice on mRNA extraction and two anonymous reviewers for their detailed comments to improve our manuscript. We are also grateful to Hiroyuki Fukuoka for permitting us to use the read2Marker script before its publication. Some of the calculations were carried out at the Computer Center of Agriculture, Forestry and Fisheries Research, MAFF, Japan. Financial support was provided by a grant from the JSPS Research Fellowships for Young Scientists program to S.U. (03J08415); the Environmental Research and Technology Development Fund from the Ministry of the Environment, Government of Japan; and Grant-in-Aid for Scientific Research (A) (KAKENHI (20241055)).

\section{Literature Cited}

Alonso-Blanco, C., M.G. Aarts, L. Bentsink, J.J. Keurentjes, M. Reymond, D. Vreugdenhil and M.Koornneef (2009) What has natural variation taught us about plant development, physiology, and adaptation? Plant Cell 21: 1877-1896.

Al-Shahrour,F., R.Diaz-Uriarte and J.Dopazo (2004) FatiGO: a web 
tool for finding significant associations of Gene Ontology terms with groups of genes. Bioinformatics 20: 578-580.

Altschul,S.F., W.Gish, W.Miller, E.W.Myers and D.J.Lipman (1990) Basic local alignment search tool. J. Mol. Biol. 215: 403-410.

Audic,S. and J.M.Claverie (1997) The significance of digital gene expression profiles. Genome Res. 7: 986-995.

Chakravarti,A. (2001) To a future of genetic medicine. Nature 409: 822-823.

Chang, S., J.Puryear and J.Cairney (1993) A simple and efficient method for isolating RNA from pine trees. Plant Mol. Biol. Rep. 11: 113-116.

Cho,Y.G., T.Ishii, S.Temnykh, X.Chen, L.Lipovich, S.R.McCouch, W.D.Park, N.Ayres and S.Cartinhour (2000) Diversity of microsatellites derived from genomic libraries and GenBank sequences in rice (Oryza sativa L.). Theor. Appl. Genet. 100: 713-722.

Conesa,A., S.Gotz, J.M.Garcia-Gomez, J.Terol, M.Talon and M. Robles (2005) Blast2GO: a universal tool for annotation, visualization and analysis in functional genomics research. Bioinformatics 21: 3674-3676.

Conesa,A. and S.Gotz (2008) Blast2GO: A Comprehensive Suite for Functional Analysis in Plant Genomics. Int. J. Plant Genomics 2008: 619832.

Darwin,C. (1880) The different forms of flowers on plants of the same species. Murray, London, p. 352.

ElMousadik, A. and R.J.Petit (1996) High level of genetic differentiation for allelic richness among populations of the argan tree (Argania spinosa (L.) Skeels) endemic to Morocco. Theor. Appl. Genet. 92: 832-839.

Environment Agency of Japan (2000) Threatened Wild Life of Japan. Red Data Book, 2nd edn, vol. 8, Vascular Plants. Japan Wild Life Research Center, Tokyo, p. 660.

Ewing, B. and P.Green (1998) Base-calling of automated sequencer traces using phred. II. Error probabilities. Genome Res. 8: 186-194.

Ewing,B., L.Hillier, M.C.Wendl and P.Green (1998) Base-calling of automated sequencer traces using phred. I. Accuracy assessment. Genome Res. 8: 175-185.

Friedman,M. (1937) The use of ranks to avoid the assumption of normality implicit in the analysis of variance. J. Am. Stat. Assoc. 200: 675-701.

Fukuoka,H., T.Nunome, Y.Minamiyama, I.Kono, N.Namiki and A.Kojima (2005) Read2Marker: a data processing tool for microsatellite marker development from a large data set. Biotechniques 39: 472, 474, 476.

Goudet,J. (1995) FSTAT (Version 1.2): A computer program to calculate F-statistics. J. Hered. 86: 485-486.

Green,P. (1999) Documentation for phrap and cross_match. [online] Available from http://bozeman.mbt.washington.edu/phrap.docs/ phrap.html.

Gupta,P.K., S.Rustgi and R.R.Mir (2008) Array-based high-throughput DNA markers for crop improvement. Heredity 101: 5-18.

Harris,M.A., J.Clark, A.Ireland, J.Lomax, M.Ashburner, R.Foulger, K.Eilbeck, S.Lewis, B.Marshall, C.Mungall et al. (2004) The Gene Ontology (GO) database and informatics resource. Nucleic Acids Res. 32: D258-261.

Holm, S. (1979) A simple sequentially rejective multiple test procedure. Scand. J. Stat. 6: 65-70.

Honjo, M., S.Ueno, Y.Tsumura, I. Washitani and R.Ohsawa (2004) Phylogeographic study based on intraspecific sequence variation of chloroplast DNA for the conservation of genetic diversity in the Japanese endangered species Primula sieboldii. Biol. Conserv. 120: $211-220$.
Honjo,M., T.Handa, Y.Tsumura, I.Washitani and R.Ohsawa (2008) Origins of traditional cultivars of Primula sieboldii revealed by nuclear microsatellite and chloroplast DNA variations. Breed. Sci. 58: $347-354$.

Honjo, M., N.Kitamoto, S.Ueno, Y.Tsumura, I. Washitani and R. Ohsawa (2009) Management units of the endangered herb Primula sieboldii based on microsatellite variation among and within populations throughout Japan. Conserv. Genet. 10: 257-267.

Horvath,D.P., J.V.Anderson, W.S.Chao and M.E.Foley (2003) Knowing when to grow: signals regulating bud dormancy. Trends Plant Sci. 8: 534-540.

Isagi,Y., M.Honjo and I.Washitani (2001) Development of microsatellite markers for Primula sieboldii using degenerate oligonucleotideprimed PCR-amplified DNA. Mol. Ecol. Notes 1: 22-24.

Iseli,C., C.V.Jongeneel and P.Bucher (1999) ESTScan: a program for detecting, evaluating, and reconstructing potential coding regions in EST sequences. Proc. Int. Conf. Intell. Syst. Mol. Biol.: 138-148.

Ishihama,F., S.Ueno, Y.Tsumura and I.Washitani (2006) Effects of density and floral morph on pollen flow and seed reproduction of an endangered heterostylous herb, Primula sieboldii. J. Ecol. 94: 846-855.

Iwatsuki,K. (2008) Endangered vascular plants in Japan-Present status and a proposal for conservation-. Proc. Jpn. Acad., Ser. B 84: 275-286.

Khlestkina,E.K. and E.A.Salina (2006) SNP markers: methods of analysis, ways of development, and comparison on an example of common wheat. Genetika 42: 725-736.

Kitamoto, N., M. Honjo, S. Ueno, A. Takenaka, Y.Tsumura, I. Washitani and R.Ohsawa (2005) Spatial genetic structure among and within populations of Primula sieboldii growing beside separate streams. Mol. Ecol. 14: 149-157.

Kitamoto,N., S.Ueno, Y.Tsumura, I.Washitani and R.Ohsawa (2005) Development of microsatellite markers in Primula sieboldii E. Morren, a threatend herb. Jpn J. Conserv. Ecol. 10: 47-51.

Kitamoto, N., S.Ueno, A.Takenaka, Y.Tsumura, I. Washitani and R.Ohsawa (2006) Evaluation of the effect of flowering phenology on pollen flow distance, and their consequence for spatial genetic structure within a population of Primula sieboldii (Primulace). Am. J. Bot. 93: 226-233.

Kondo,H., T.Tahira, H.Hayashi, K.Oshima and K.Hayashi (2000) Microsatellite genotyping of post-PCR fluorescently labeled markers. Biotechniques 29: 868-872.

Kumpatla, S.P. and S.Mukhopadhyay (2005) Mining and survey of simple sequence repeats in expressed sequence tags of dicotyledonous species. Genome 48: 985-998.

Leberg,P.L. (2002) Estimating allelic richness: effects of sample size and bottlenecks. Mol. Ecol. 11: 2445-2449.

Li,J., M.Webster, M.Furuya and P.M.Gilmartin (2007) Identification and characterization of pin and thrum alleles of two genes that cosegregate with the Primula S locus. Plant J. 51: 18-31.

Li,S. and H.H.Chou (2004) LUCY2: an interactive DNA sequence quality trimming and vector removal tool. Bioinformatics 20: 2865-2866.

Parkinson,J., D.B.Guiliano and M.Blaxter (2002) Making sense of EST sequences by CLOBBing them. BMC Bioinformatics 3: 31 .

Parkinson, J., A. Anthony, J. Wasmuth, R. Schmid, A. Hedley and M.Blaxter (2004) PartiGene - constructing partial genomes. Bioinformatics 20: 1398-1404.

Pashley,C.H., J.R.Ellis, D.E.McCauley and J.M.Burke (2006) EST databases as a source for molecular markers: lessons from Helianthus. J. Hered. 97: 381-388. 
Pati,N., V.Schowinsky, O.Kokanovic, V.Magnuson and S. Ghosh (2004) A comparison between SNaPshot, pyrosequencing, and biplex invader SNP genotyping methods: accuracy, cost, and throughput. J. Biochem. Biophys. Methods 60: 1-12.

Quevillon,E., V.Silventoinen, S.Pillai, N.Harte, N.Mulder, R.Apweiler and R.Lopez (2005) InterProScan: protein domains identifier. Nucleic Acids Res. 33: W116-120.

Richards,J. (2003) Primula. Timber press, Portland, Oregon, p. 346.

Rousset,F. (2008) Genepop'007: a complete reimplementation of the Genepop software for Windows and Linux. Mol. Ecol. Resour. 8: 103-106.

Rozen,S. and H.J.Skaletsky (2000) Primer3 on the WWW for general users and for biologist programmers. In: Krawetz, S.A. and S.Misener (eds.) Bioinformatics Methods and Protocols: Methods in Molecular Biology, Humana Press, Totowa, pp. 365-386.

Temnykh, S., G.DeClerck, A.Lukashova, L.Lipovich, S.Cartinhour and S.McCouch (2001) Computational and experimental analysis of microsatellites in rice (Oryza sativa L.): frequency, length variation, transposon associations, and genetic marker potential. Genome Res. 11: 1441-1452.

Torii,T. (1985) Sakurasou, Nihon-TV, Tokyo, p. 151.

Ueno,S., Y.Tsumura and I.Washitani (2003) Development of microsatellite markers in Primula sieboldii E. Morren, a threatened Japanese perennial herb. Conserv. Genet. 4: 809-811.

Ueno,S., N.Kitamoto, R.Ohsawa, Y.Tsumura and I.Washitani (2005) Nine additional microsatellite markers for Primula sieboldii E. Morren. Conserv. Genet. 6: 1063-1064.

Ueno, S., Y.Taguchi and Y.Tsumura (2008) Microsatellite markers derived from Quercus mongolica var. crispula (Fagaceae) inner bark expressed sequence tags. Genes Genet. Syst. 83: 179-187.

Ueno, S., K.Aoki and Y.Tsumura (2009a) Generation of Expressed Sequence Tags and development of microsatellite markers for Castanopsis sieboldii var. sieboldii (Fagaceae). Ann. For. Sci. 66:
509

Ueno,S., Y.Yoshida, Y.Taguchi, M.Honjo, N.Kitamoto, I.Washitani, R. Ohsawa and Y.Tsumura (2009b) Development of 120 microsatellite markers for Primula sieboldii E. Morren for linkage mapping. Conserv. Genet. 10: 1945-1952.

Washitani,I. (1996) Predicted genetic consequences of strong fertility selection due to pollinator loss in an isolated population of Primula sieboldii. Conserv. Biol. 10: 59-64.

Washitani, I. (1998) Primula eye: what is conservation ecology? Chijinshokan, Tokyo, p. 229.

Yamaguchi,S. (1973) Cytogenetical studies in Primula sieboldii E. Morren: Chromosome numbers of 80 cultivars and related wild species. Jpn. J. Breed. 23: 86-92.

Yamazaki, T. (1993) Primula. In: Iwatsuki, K., T.Yamazaki, D.E. Boufford and H.Ohba (eds.) Flora of Japan 3a, Kodansha, Tokyo, pp. 87-94.

Yoshida,Y., M.Honjo, N.Kitamoto and R.Ohsawa (2008) Genetic variation and differentiation of floral morphology in wild Primula sieboldii evaluated by image analysis data and SSR markers. Breed. Sci. 58: 301-307.

Yoshida,Y., M.Honjo, N.Kitamoto and R.Ohsawa (2009) Reconsideration for conservation units of wild Primula sieboldii in Japan based on adaptive diversity and molecular genetic diversity. Genet. Res. 91: 225-235.

Yoshida,Y., S.Ueno, M.Honjo, N.Kitamoto, M.Nagai, I.Washitani, Y.Tsumura, Y.Yasui and R. Ohsawa (2011) QTL analysis of heterostyly in Primula sieboldii and its application for morph identification in wild pupulations. Ann. Bot. 108: 133-142.

Yoshioka, Y., H.Iwata, R. Ohsawa and S.Ninomiya (2005) Quantitative evaluation of the petal shape variation in Primula sieboldii caused by breeding process in the last 300 years. Heredity 94 : $657-$ 663. 